This item was submitted to Loughborough's Research Repository by the author.

Items in Figshare are protected by copyright, with all rights reserved, unless otherwise indicated.

\title{
Briefing: sustainable drainage for sports pitch developments
}

PLEASE CITE THE PUBLISHED VERSION

http://www.icevirtuallibrary.com/content/serial/muen

\section{PUBLISHER}

(C) ICE Publishing

\section{VERSION}

VoR (Version of Record)

\section{PUBLISHER STATEMENT}

This work is made available according to the conditions of the Creative Commons Attribution-NonCommercialNoDerivatives 4.0 International (CC BY-NC-ND 4.0) licence. Full details of this licence are available at: https://creativecommons.org/licenses/by-nc-nd/4.0/

\section{LICENCE}

CC BY-NC-ND 4.0

\section{REPOSITORY RECORD}

Simpson, Murray R., Paul R. Fleming, and Matthew W. Frost. 2019. "Briefing: Sustainable Drainage for Sports Pitch Developments". figshare. https://hdl.handle.net/2134/17254. 


\section{Briefing: Sustainable drainage for sports pitch developments}

Murray R. Simpson MSC

PhD research student, School of Civil and Building Engineering, Loughborough University, Leicestershire, UK

Paul R. Fleming BEng, PhD, MIHT

Academic supervisor, School of Civil and Building Engineering,

Loughborough University, Leicestershire, UK
Matthew w. Frost BEng, DIS, PhD, PgCHE, MPWI

Academic supervisor, School of Civil and Building Engineering, Loughborough University, Leicestershire, UK

Effective management of storm water is of paramount importance in urban development, and drainage design is usually governed by planning constraints. In the development of sports pitches, planning bodies often impose discharge constraints, and frequently class such areas as impermeable surfaces, thus treating their drainage behaviour in a similar fashion to roads and pavements, which may require the provision of separate attenuation. This briefing presents preliminary findings of a project to assess the drainage behaviour of sports pitch developments. The work undertaken to date suggests only a fraction of water falling on a pitch (rain) is discharged to the drains, identifying an apparent attenuation capacity and potential over-design within current sports pitch drainage systems. In addition to the low discharge volumes measured from pitch systems, there has also been a broad range of flow rates experienced. This led to the development of a bespoke flow monitoring device, FloPod. Designed and fabricated at Loughborough University, this device allows a broad range of flow rates to be measured without compromising aspects of data resolution and reliability - key factors that were not found in commercially available devices.

\section{Introduction}

Planning authorities impose strict drainage water discharge constraints for new developments, demanding often comprehensive drainage systems as part of the design. Within planning it is not uncommon for sports pitches to be treated as an impermeable area (like roads or car parks), which assumes that all the rainfall that lands on the pitch is collected by the drains and then needs to be discharged off site. A typical sports development can have a number of pitches, which can cover a comparatively large area (7000-11 $000 \mathrm{~m}^{2}$ for a single full-sized outdoor pitch) such that predicted runoff volumes can be large for intense rainfall events. These assumptions regarding the drainage behaviour of pitches result in the installation of large, expensive, separate attenuation tanks, which may be required to control the discharge rate to acceptable levels. However, the effective prediction of the volume of water collected by and discharged from a sports pitch is not without some complexity and current designs are simplistic and empirical.

Outdoor natural and artificial turf pitches (in particular) feature a number of permeable layers that are designed to allow surface water to penetrate into the system and thus have the potential to provide both the capacity for attenuation and also additional storage. The sports surface industry has increasingly questioned the need for separate off-line storage in the form of large storage tanks, based on observation of low water volumes seen flowing at drainage outfalls or collected in storage tanks.

Current sports pitch drainage design in practice does not follow robust or rigorous methods for estimating the potential storage and attenuation capacity of sports pitch constructions. It is believed by many that a sports pitch drainage behaviour mimics many of the principles encompassed in 'source control' within sustainable urban drainage system best practice (Wilson et al., 2004). The lack of data and understanding of sports pitch drainage is leading to a high degree of over-design to meet imposed discharge constraints. Commonly this can be based on questionable assumptions, such as the surface water that infiltrates into the pitch is equal to the water measured at the point of discharge from the drainage system (i.e. water in = water out).

It is thus necessary to understand the physical interaction between the rainfall and the sports pitch construction system (i.e. surfacing, foundations and sub-surface drainage). If the hydraulic behaviour of sports pitches is better understood then it will be possible to

- establish the natural attenuation and storage capacity of pitches

determine if there is spare storage capacity to integrate 
with the wider urban environment (adding 'value' to the sports facility)

update current design guidance and ideally influence planning policy guidance.

This brief document describes part of an on-going research project at Loughborough University, aimed primarily at fieldwork collecting flow measurements of sports pitch drainage behaviour.

\section{Characterising drainage behaviour}

Figure 1 presents a simple cross-section of a typical artificial pitch construction. This form of porous, layered construction is typical of that utilised for a range of outdoor sports (SAPCA, 2009) with the surface system changed to suit any specific sport. The factors considered to affect the expected drainage of the layers, divided into three zones, are included in the figure. The pitch profile is separated into three zones, here based on grouping the layer material types and how these are expected to control the movement and potential storage of water.

Zone 1 comprises the synthetic turf carpet, usually fibres tufted into a backing material with an infill material consisting of a fine $(0 \cdot 2-0 \cdot 7 \mathrm{~mm})$ sand lower layer and a fine recycled rubber 'crumb' $(0 \cdot 5-2 \cdot 0 \mathrm{~mm})$ upper infill layer worked into the spaces between the tufted fibres. The carpet backing usually has a latex coating to help secure the fibres and, to assist throughdrainage, holes punched during the carpet construction sequence, between 5 and $10 \mathrm{~mm}$ in diameter and spaced approximately 100-200 mm apart. Beneath the carpet a shockabsorbing layer (usually $10-30 \mathrm{~mm}$ thick) provides aspects of sports performance (player comfort). Many varieties exist, a common system in the UK comprises coarse rubber crumb (2$8 \mathrm{~mm}$ ) bound with a polyurethane adhesive manufactured in situ and is very porous. Little is known about the movement of water in this upper zone of the system, but it has been observed that for low-intensity rainfall the water may not actually penetrate into the lower layers.

Zone 2, termed the 'foundation', comprises an open, graded, porous macadam layer (typically $65 \mathrm{~mm}$ thick) constructed onto a 'low-fines' aggregate sub-base layer (typically $300 \mathrm{~mm}$ thick or more). These two layers form a flat and stable base with a long design life, which is similar in design to a porous car park. The void space in these layers is typically $10-20 \%$. The high permeability and large void space (up to $500 \mathrm{~m}^{3}$ ) are key factors affecting water flow and storage. It is also considered that large volumes of water can be adsorbed onto the particle surfaces in these layers, dependent on the antecedent rainfall conditions.

Zone 3 comprises the natural sub-soil 'formation'. The subsurface drainage system comprises $100-\mathrm{mm}$ diameter perforated pipes running diagonally across the pitch at $10-15 \mathrm{~m}$ centres, joined to a perimeter drain (usually $150 \mathrm{~mm}$ in diameter) (SAPCA, 2009). This system usually discharges to a single outfall. Drainage pipes are specified to a minimum fall of 1200, in excavated trenches backfilled with single-sized, rounded gravel $(5-10 \mathrm{~mm})$. An impermeable geomembrane or similar liner can be used to provide a barrier at the base to permit collection of drainage water for reuse or to protect underlying aquifers. There exists large capacity for water to be held or stored in this lower layer, or more significantly for natural attenuation by exfiltration into the sub-soil (if permeable with a water table well below formation) whereby the pitch can act as a large soakaway. These pertinent aspects of sub-soil are rarely targeted in sports pitch site investigations; however, extensive field monitoring of existing sports pitches is currently underway within the overall research programme. The fieldwork is comparing the measured drainage discharge data with precipitation measurements (recorded in millimetres by a rain gauge), permitting analysis of the water in against water out. Preliminary results have recorded extremely low discharge rates and volumes from a range of rainfall events at several sites. In general, approximately $10-20 \%$ of the rainfall volume has been observed as being discharged, supporting anecdotal industry experience. Theoretical predictions will further support and validate the field data.

A key objective challenge for the effective field monitoring of pitch outflows was to capture accurately the range of discharges experienced. Preliminary data have shown that these can range from $0.015 \mathrm{l} / \mathrm{min}$ to over $70 \mathrm{l} / \mathrm{min}$. Initial monitoring was carried out using a commercially available ultrasonic flow-measuring device. The sensor detects both water depth and velocity in a specific-sized flow channel. However, for extremely low discharge rates these were well below the calibrated detection limit of the device. Attempts were made to modify this system to improve precision, and to investigate alternative commercial apparatus suitable for the job, but these proved fruitless. The decision was then made to develop in house a bespoke system capable of collecting data for a broad range of flow rates.

\section{FloPod discharge measurement system development}

The portable flow monitoring device, FloPod, was designed to be flexible in its range of flow measurement, be easily installed into a range of outfall chambers encountered on site, and have appropriate capacity for battery power and data storage to require only occasional visits to the installation to collect the data and service the apparatus. The flow measurement system is similar to a tipping bucket flow-meter (Hollis and Ovenden, 1987), whereby tipping bucket devices count the number of times that buckets of a fixed volume are filled and emptied over time. The FloPod monitoring system features an internal 
Municipal Engineer

Volume 166 Issue ME4
Briefing: Sustainable drainage

for sports pitch developments

Simpson, Fleming and Frost

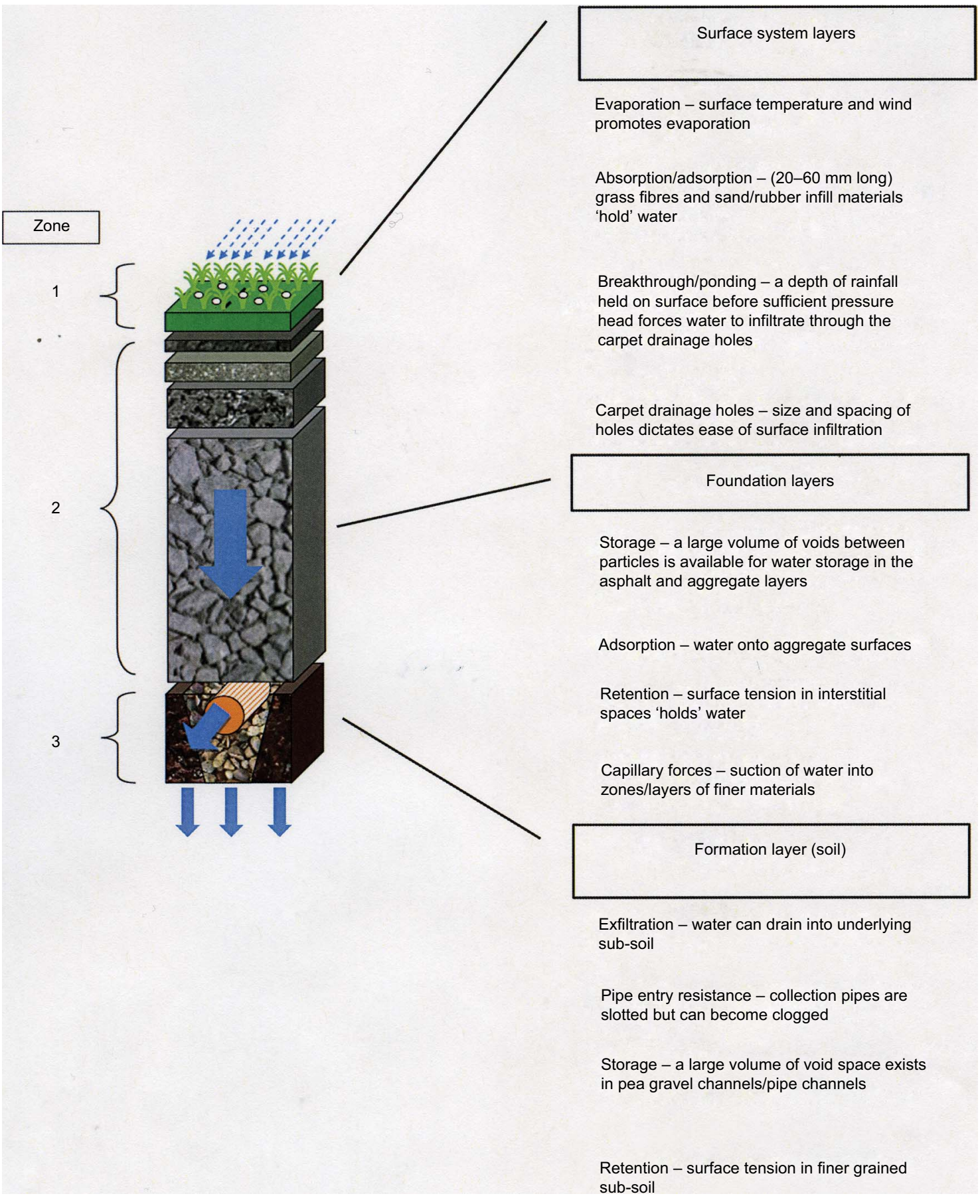

Figure 1. Cross-section of a typical artificial pitch construction showing the different layers of materials and the factors and mechanisms that can affect hydraulic behaviour

reservoir and float switches connected to a pumping system and outflow meter. A data-logger records the times the pumps are active and the volume discharged. The time duration of pumping and the volume of water pumped out in combination provide the discharge rate of the pitch at the outfall. The drainage discharge rate can be plotted on a graph with the 


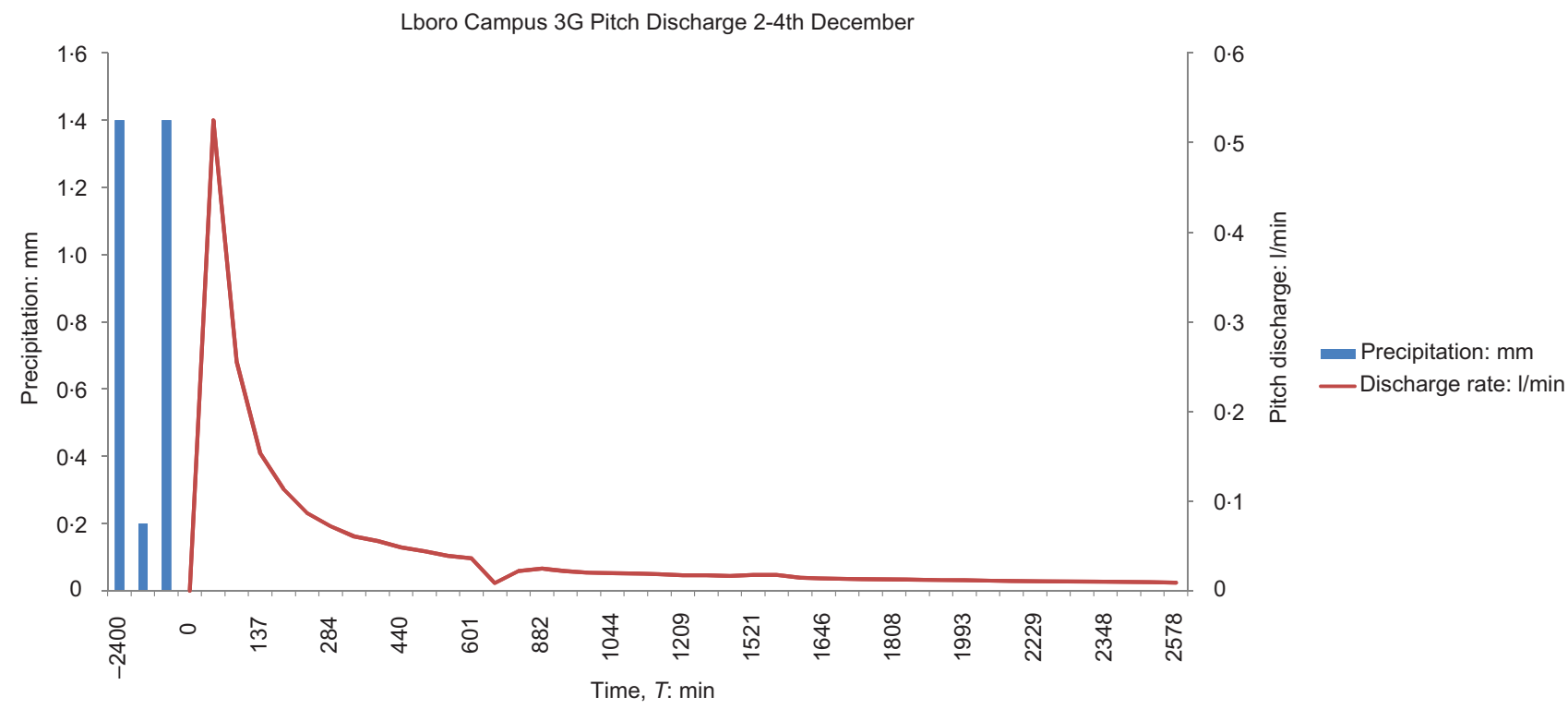

Figure 2. Example pitch hydrograph

rainfall data, on a time base, to produce a sports pitch hydrograph (as shown in Figure 2).

The example hydrograph presented in Figure 2 shows the total precipitation in millimetres (from which volume 'in' can be calculated) in bar chart form and the volume 'out' as a drainage rate discharge curve on the same graph. The chart can show the time lag between rainfall and the discharge water to appear at the outfall and time for dissipation. From the current collection of pitch hydrographs, it has been

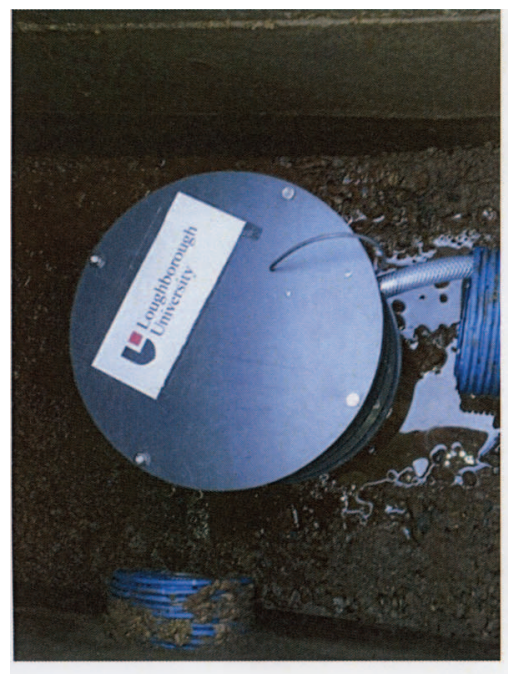

(a)

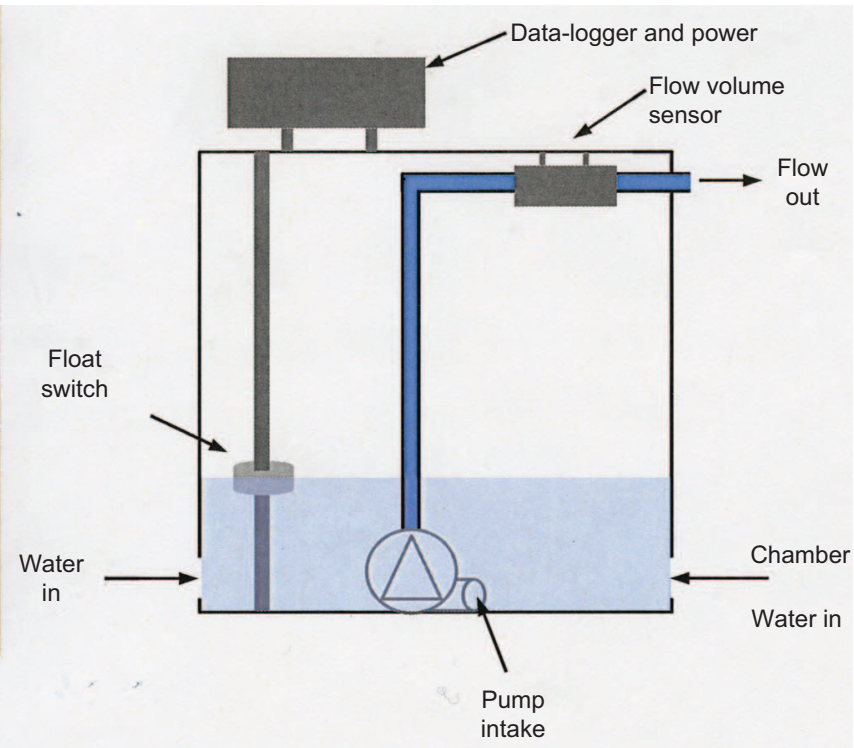

(b)

Figure 3. FloPod: (a) installed in a typical drainage system collection chamber and (b) cross-section giving a schematic representation of the internal layout and components 
possible to estimate that approximately $0-10 \%$ of volume 'in' is measured as pitch discharge (volume 'out'). Figure 3 shows an early model of FloPod in situ and a cross-section showing the internal components. When assessing suitable locations for monitoring through a site screening procedure, focus is given to the condition of the drainage system and chamber where FloPod will be located. A good-quality chamber would be sealed, allowing all water to be captured by FloPod. However, if the chamber is not sealed, FloPod would be installed in a small tank, into which any inflowing water would be directed. The current system has a working range of $0-50 \mathrm{l} / \mathrm{min}$, although the system is capable of being upgraded to handle a higher capacity without affecting lower working limits.

Capturing discharge data at high resolution has been a key design criterion. In addition, a number of design factors have been balanced to ensure system reliability over time in a harsh environment. Balancing pumping capacity and frequency of operation required with power consumption has been a challenge in the development of FloPod. Refinements have to date produced three FloPod prototypes.

\section{Acknowledgements}

This project is funded by Loughborough University through its graduate school programme, with external funding support from Sport England (SE) and the Institute of Groundsmanship (IOG). Further advisory support has been provided by the Sport and Play Construction Association (SAPCA) and the Sports Turf Research Institute (STRI).

\section{REFERENCES}

Hollis GE and Ovenden JC (1987) A tipping bucket flowmeter for roadside gully runoff. Hydrological Processes 1(4): 391-396. SAPCA (The Sport and Play Construction Association) (2009)

Code of Practice for the Construction and Maintenance of Artificial Sports Pitches. SAPCA, Warwickshire, UK.

Wilson S, Bray R and Cooper P (2004) Sustainable Urban Drainage Systems: Hydraulic, Structural and Water Quality Advice. CIRIA, London, UK, C609.

\section{WHAT DO YOU THINK?}

To discuss this briefing, please email up to 500 words to the editor at journals@ice.org.uk. Your contribution will be forwarded to the author(s) for a reply and, if considered appropriate by the editorial panel, will be published as discussion in a future issue of the journal.

Proceedings journals rely entirely on contributions sent in by civil engineering professionals, academics and students. Papers should be 2000-5000 words long (briefing papers should be 1000-2000 words long), with adequate illustrations and references. You can submit your paper online via www.icevirtuallibrary.com/content/journals, where you will also find detailed author guidelines. 